\title{
A chemical switch system to modulate Chimeric Antigen Receptor (CAR) T cell activity through Proteolysis-targeting chimaera (PROTAC) technology
}

So Myoung Lee ${ }^{\dagger, *}$, Chung Hyo Kang ${ }^{\dagger,+, *}$, Sang Un Choi ${ }^{\dagger}$, Yeongrin $\mathrm{Kim}^{\dagger, \|}$, Jong Yeon Hwang ${ }^{\dagger, \|,}$ Hye Gwang Jeong $¥$, Chi Hoon Park ${ }^{\dagger, \|, \#}$

† Bio \& Drug Discovery Division, Korea Research Institute of Chemical Technology, PO Box 107, Daejeon 305-600, Republic of Korea

$\ddagger$ College of Pharmacy, Chungnam National University, Daejeon, Korea

" Medicinal \& Pharmaceutical Chemistry, Korea University of Science and Technology, Daejeon 305-350, Republic of Korea 


\section{Supplementary Method}

The followings are primer sequence used in this paper.

Flag-KRas-BD2 :

Primer 1 (Ras_Flag_F_XhoI) : atc tct CTCGAG ATG GAC TAC AAA GAC GAT GAC GAC AAG ATG ACT GAA TAT AAA CTT

Primer 2 (BD2_STOP_R_BamHI): atc tct GGATCC TTACTCGTCCGGCATCTTGGC

Primer 3 (Ras-BD2_F): ACAAAGTGTGTAATTATG ccag caccagagaa gagcagca

Primer 4 (Ras-BD2_R): TGCTGCTCTTCTCTGGTGCTGGCATAATTACACACTTTGT

Flag-IDH1-BD2 :

Primer 1 (IDH1_Flag_F_XhoI): atc tct CTCGAG ATG GAC TAC AAA GAC GAT GAC GAC AAG atgtccaaaaaaatc agt

Primer 2 (BD2_STOP_R_BamHI): atc tct GGATCC TTACTCGTCCGGCATCTTGGC

Primer 3 (IDH1-BD2_F): ctagctcaggc caaactt ccag caccagagaa gagcagca

Primer 4 (IDH1-BD2_R): TGCTGCTCTTCTCTGGTGCTGGAAGTTTGGCCTGAGCTAG 


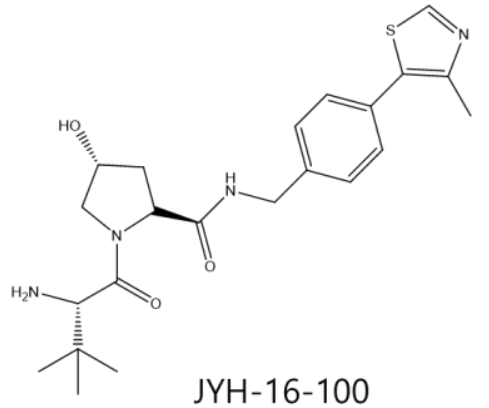

JYH-16-100

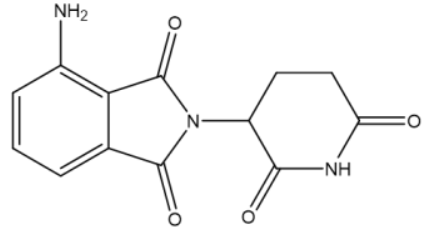

POMALIDOMIDE

Supplementary Figure 1

Supplementary figure 1

The structure of ligands of VHL and CRBN 

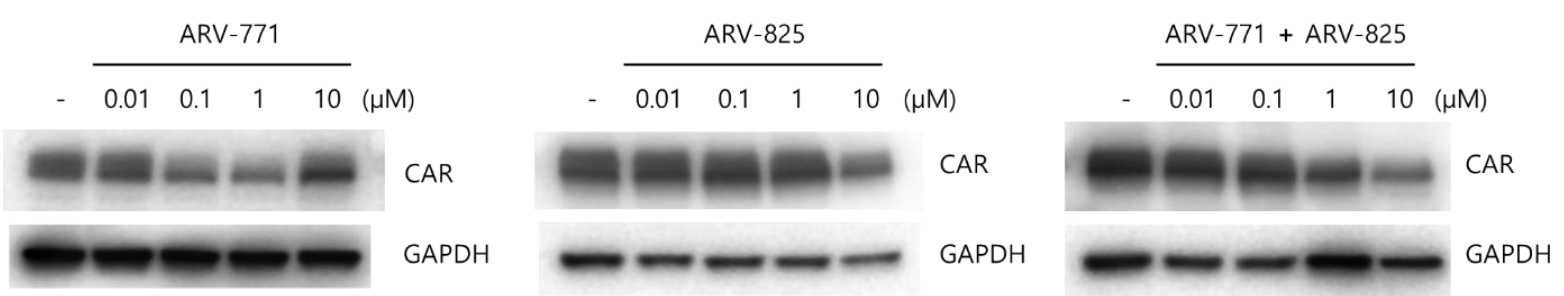

Supplementary Figure 2

Supplementary figure 2

293T cells transfected with FMC63-28-BD2-z construct were treated with ARV-771, ARV-825, or ARV-771 + ARV-825 as indicated concentration. After $15 \mathrm{hr}$, cell lysates were prepared. Western blot was performed with CD3z antibody (CAR) and GAPDH antibody. 


\section{A ARV771+ARV825}

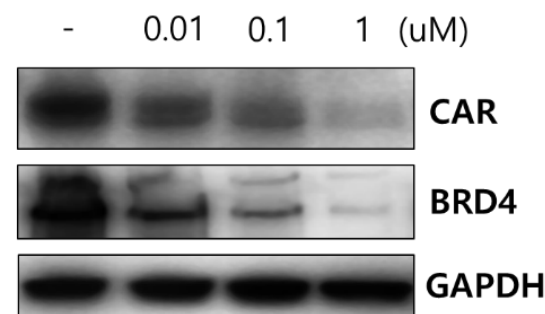

B

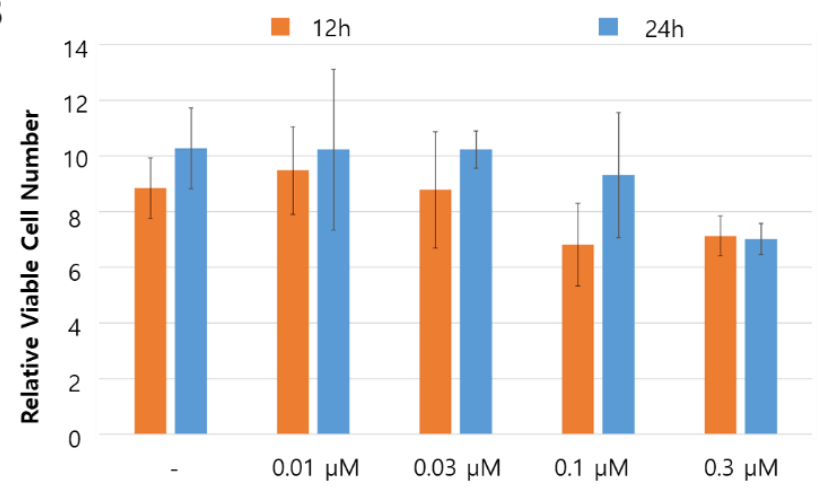

Supplementary Figure 3

Supplementary figure 3

(A) FMC63-28-BD2-z KHYG-1 cells were treated with ARV771+ARV825 as indicated concentration. After $12 \mathrm{hr}$, cell lysates were prepared. Western blot was performed with CD3z antibody (CAR), BRD4 antibody, and GAPDH antibody.

(B) FMC63-28-BD2-z KHYG-1 cells were treated with ARV $771+$ ARV825 as indicated concentration. After $12 \mathrm{~h}$ or $24 \mathrm{~h}$, viable cells were counted. 